Marquette University

e-Publications@Marquette

$1-1-1988$

\title{
City Size, Quality of Life, and the Urbanization Deflator of the GNP: 1910-1984
}

David E. Clark

Marquette University, david.clark@marquette.edu

James R. Kahn

State University of New York at Binghamton

Haim Ofek

State University of New York at Binghamton

Published version. Southern Economic Journal, Vol. 54, No. 3 (January 1988): 701-714. DOI. (C) 1988 Southern Economic Association. Used with permission. 


\title{
City Size, Quality of Life, and the Urbanization Deflator of the GNP: 1910-1984*
}

\author{
DAVID CLARK \\ Marquette University \\ Milwaukee, Wisconsin
}

JAMES R. KAHN

State University of New York at Binghamton

Binghamton, New York

HAIM OFEK

State University of New York at Binghamton

Binghamton, New York

\section{Introduction}

City size affects quality of life through a wide and diverse set of conflicting amenities and disamenities. Big city residents suffer from the ill effects of congestion, pollution, crime, noise, expensive housing, long and stressful commutes, and other adversities typical to heavily populated metropolitan centers. Big city residents enjoy however certain privileges that their counterparts in smaller cities or in rural areas do not: a wide range of highly specialized goods and services accompanied by a variety of cultural, recreational, educational and employment opportunities-to name but the most obvious. It follows that while in certain respects quality of life deteriorates with city size, in other respects it may actually improve. This study is an attempt to determine, on balance, the net effect of these conflicting forces. We do not plan to be overly descriptive about the roles played by specific amenities or disamenities. Instead, the analysis is carried out with the intent of devising a generic measure of quality of life which is sensitive to changes in city size. Although such a "catchall" measure should be qualified in a number of ways, it remains a sufficiently useful deflator for the purpose of adjusting GNP and other welfare indices.

Quality of life depends to a great extent on goods for which explicit markets do not exist. In order to quantify quality of life in a given situation it is necessary to devise measures of willingness to pay for such nonmarket goods. A number of implicit markets pricing techniques have been developed. One approach which has been utilized in the recent literature is based on compensating wage differentials (Hall [2], Henderson [3], Hoch [5], Lucas [8], Robuck [12],

*We are grateful to Charng Kao and Yesook Merill for valuable computational assistance. A large number of individuals made helpful comments on earlier drafts of this paper. We would like particularly to thank Jacob Mincer and Phillip Nelson for their constructive criticism. We also acknowledge the very intriguing questions posed by an anonymous referee that helped improve the final draft. None of the aforementioned are responsible however for the views expressed in this paper or for any remaining mistakes. 
Rosen [13], Thaler and Rosen [15]). While adopting and marginally advancing the principle of wage differentials, the present study differs from others in that the principle is directly applied to a generic measure of amenities (city size), rather than to any specific urban amenity.

The underlying assumption in applying compensating wage differentials is that certain amenities are capitalized into wages as workers optimize residential location. Yet, a question arises in light of another body of literature also concerned with the evaluation of locational amenities: the hedonic housing price approach (e.g., Freeman [1], Henning and Ridker [4], Polinsky and Rubinfeld [11]). To what extent are variations in the level of amenities captured in housing (or land) prices and to what extent are they captured in wages? The risk of double counting calls for a clear demarcation rule. Henderson [3] has derived such a rule based on a distinction between variations in the level of amenities within a city, and variations in the level of amenities across cities. Under plausible conditions the former are fully capitalized into housing prices, and the latter are fully capitalized into wages. Since city size can vary only across cities its consequences would be capitalized into intercity wage differentials. As it turns out, variations in urban wage rates may in a profound way contain sufficient information to establish a welfare measure of urbanization. The tasks of deriving such a measure and its estimation are undertaken in what follows.

The estimation procedure suggested in the theoretical part of the paper (section II) is implemented in the empirical part (section III) using 1980 census data from the PUMS (Public Use Micro Data Sample). The results indicate there is no single optimal city size, but rather a worst city size, and about 90 percent of the U.S. population reside in cities smaller than worst city size. If quality of life is related to the degree of urbanization, then long-term trends in the locational distribution of the population should be accounted for in any welfare-oriented measure of national income. One application of our results is, as indicated, the derivation of a GNP welfare deflator reflecting changes in the degree of urbanization (section IV). The findings suggest an urban deflator on the order of six to seven percentage points, which is steadily increasing at a rate of about half a percentage point per decade.

\section{Formal Analysis}

\section{Definitions and Assumptions}

A system of cities is viewed as a geographic network of imperfectly segmented markets over which capital goods and labor are mobile according to the following conditions:

i. Capital is costlessly mobile within and across cities in the long-run, but not in the shortrun.

ii. Goods are characterized as either export goods or local goods. Export goods are costlessly mobile across cities and traded in national markets. Local goods (e.g., housing) are immobile across cities and traded locally.

iii. Labor is assumed to be mobile across cities in terms of migration but not in terms of commutation. The distinction between migration and commutation is essential since migration costs are incurred on a life-time basis, whereas commuting costs are incurred on a daily basis. In accordance with this principle, a worker would face prohibitively high costs of commuting between cities, finite costs of commuting within a city, and only negligible cost of migration within and across cities. 
Given the nature of the following analysis cities are most usefully viewed as "open" and "monocentric" local labor markets. The cities are "open" in the sense that each city is assumed to border on agricultural land into which it can indefinitely expand as long as urban users (households and firms) can bid land away from agriculture. In other words, workers are free to cross suburban jurisdiction lines and obtain employment regardless of residential location, despite restrictions such lines may pose on some other activities (notably, taxation and provision of public services). Corresponding to the open city concept, agriculture is assumed to command a bid rental price for land which is the same throughout the system, except for random variations.'

Cities are assumed to be monocentric in the sense that workers are employed at the center. This is a standard simplifying restriction that can be relaxed without affecting the fundamentals of the present analysis. ${ }^{2}$ The simplest version of the model is based on the assumption that urban households consist of equally productive full time wage earners. This assumption and an accompanying simplifying assumption that workers do not hold income producing assets are treated and eventually relaxed by the introduction of appropriate control variables in the course of estimation.

\section{Locational Optimization in Consumption}

The model encompasses two types of economic agents, utility-maximizing households and profitmaximizing firms operating in competitive labor, land, and capital markets. Our first concern is with households, each of which is assumed to maximize utility in consumption goods $(x)$, living space $(h)$, and two environmental variables $(N$ and $A)$.

$$
U(x, h ; N, A)
$$

where $N$ is city size (the number of full-time workers as a fixed proportion of the population), and $A$ represents an index (or a vector) of naturally occurring consumer amenities specific to the site a city is located on, but independent of its size (rain, sunshine, temperature, etc.). Since a detailed analysis of local housing markets is not a major concern in the following discussion, we may overlook consumer amenities which differ across sites within a city, so long as they do not systematically differ across cities. We cannot ignore however commuting costs which differ not only across sites but also across cities, and in fact are highly correlated with city size. The effect of commuting is introduced through the budget constraint specified below.

To eliminate unnecessary notation the units of space (by which we measure $h$ ) and the units of goods (by which we measure $x$ ) are normalized on prices; i.e., both the rental price of agricultural land and consumer prices are set equal to one. To further simplify notation, let distances within a city be measured in terms of commuting time, and let time be measured in terms of the standard work period (of full time workers). If, finally, commuting costs are evaluated by the opportunity cost of time in transportation (ignoring out of pocket expenses), then the budget constraint can be written

$$
x+r h=w(1-d) \quad(=y)
$$

1. Deviations from the "open city" format are thus associated with restricted accessibility. The most obvious examples are natural obstacles. Under restricted accessibility the rental premium on urban land (over agricultural land) may exist even at the very edge of the city. To accommodate the analysis to such a possibility the open-city assumption is relaxed at a subsequent point in the analysis (see Footnotes 4 and 5).

2. An earlier prolonged version of this paper (available from the authors on request) allowed for dispersal of employment throughout the city. Since this part of the analysis had no consequences on the final findings, it was suppressed in order to save space. 
where $w$ (the normalized wage rate) is equal to total earnings of full time workers, $r$ represents the rental price of living space, and $d$ stands for the residential distance from the center of the city in terms of commuting time. ${ }^{3}$ Since $w d$ (commuting costs) represents a cost of employment, $w(1-d)=y$ is equivalent to disposable money income. Note that under these conditions the geographic stretch of a city is limited by the constraint $d<1$, that is, a round trip edge to center of city should not exceed the working day.

Utility maximization can be broken into two steps. First, for any choice of location, maximizing (1) subject to (2) with respect only to $x$ and $h$, a partial solution is obtained in the form of an indirect utility function.

$$
V(r, w(1-d) ; N, A)
$$

In the second step (3) itself is maximized with respect to location, which consists of two components. The first component is the choice among cities, represented by the index $L$. The second component is the choice of $d$, the distance from the center of a given city. All the arguments entering the indirect utility function (3) are functions of location (functions of $L$ or $d$, or both). This is clear in the case of city size $(N=N(L))$, or $d$ itself. As for the remaining three arguments,

$$
\left.\begin{array}{rl}
r & =r(d, L), \quad \text { rental prices differ across and within cities; } \\
w & =w(L), \quad \text { wages are equalized within cities, but not across cities; } \\
A & =A(L), \quad \text { city-specific amenities differ across but not within cities. }
\end{array}\right\}
$$

Substituting from (4), and maximizing (3) with respect to location $d$ and $L$, the maximum attainable level of utility in the system is obtained as a constant $U=U^{*}$ defined by

$$
\left.\max _{d, L} V[r(d, L), w(L)(1-d) ; N(L), A(L)]=U^{*} \quad \text { (= a constant }\right) .
$$

Equation (5) may be interpreted in two ways depending on whether or not the system is in equilibrium. If the system is in disequilibrium, then (5) is an equation satisfied at a single point (say $d^{*}$ and $L^{*}$ ). On the other hand if the system is in locational equilibrium, then (5) is an identity satisfied at all points (all $d$ and $L$ ) of urban residency. In the latter case the utility function collapses to a single relevant indifference curve:

$$
V(r, w(1-d) ; N, A)=U^{*} \quad(=\text { a constant }) .
$$

Solving for $w,(6)$ becomes

$$
w=e\left(r, U^{*} ; N, A\right) /(1-d)
$$

where $e\left(r, U^{*} ; N, A\right)$ is the consumer expenditure function possessing familiar properties. Equation (7) represents a fundamental equilibrium condition. Further analysis and interpretation of this condition are now in order.

\section{Locational Equilibrium at the Edge of the City}

The derivation of conditions determined by equilibrium at the edge of the city space is a useful intermediate step in the analysis. Consider a household located along the edge of the city at a distance of $d=D$ (radius of the city) away from the center. Such a household faces a rental price equal to the agricultural rental price, $r(D)=1$. Eliminating constants, the expenditure function

3. Equation (2) is a slightly simplified version of the urban household budget constraint suggested by Hochman and Ofek [6]. 
as evaluated at city edge simplifies to $E(N, A)=e\left(1, U^{*} ; N, A\right)$. If in addition the distance to the city edge $D$ is approximated as a function of population, $D=D(N)$, then equilibrium condition (7) becomes ${ }^{4}$

$$
w=E(N, A) /[1-D(N)]
$$

The value of $w$ which solves this equation is the reservation wage rate, i.e., the minimum acceptable wage rate that would keep a household willingly located at the edge of the city. Note that (8) is an equilibrium condition that must be satisfied; otherwise, neither the geographical nor the population size of a city can remain stable. If wages fall short of $E(N, A) /(1-D)$ the inhabitants will desert the edge of the city in favor of better opportunities elsewhere, and the city will shrink. If wages exceed $E(N, A) /(1-D)$ the edge will become crowded by newcomers and be pushed further away from the center.

\section{Labor Supply to a City in a System of Cities}

The significance of the wage reservation condition (8) exceeds the simple implications concerning equilibrium at the edge of a city. In a competitive labor market (the city) workers are paid according to marginal productivity regardless of their residential location. Wage rates would tend therefore to equalize throughout the city, and thus adjust to the reservation wage rate established at edge of the city by the process outlined above. It follows that equation (7) and (8) can be linked together by a common value of $w$.

$$
e\left(r, U^{*} ; N, A\right) /(1-d)=w=E(N, A) /[1-D(N)] .
$$

The first equality in (9) demonstrates the way the rental price of housing is determined by location $(d)$ and wages $(w)$, among other variables. The second equality demonstrates how wages are determined independently of either housing costs or location. Wages, though, are shown to adjust so as to compensate (through the term $1 /(1-D)$ ) for the entire cost of commuting to the edge of the city. Wages determined in such a way remain applicable throughout the city because workers living at shorter distances from the center are "penalized" for increasing proximity $(d<D)$ by correspondingly increasing housing costs $(r>1)$ charged by rent maximizing landlords. In effect, according to (9), a household located at the center itself $(d=0)$ would need to pay a premium in rents equivalent to the entire daily trip to the edge of the city.

As it turns out, the function $w=E(N, A) /[1-D(N)]$ first obtained as merely a wagereservation condition for households at the edge of the city, can now be shown to have three additional, more profound, interpretations. First, since $w=E(N, A) /[1-D(N)]$ is independent of housing prices $r$ or location within the city $d$, it can be interpreted as a well specified (inverted) aggregate labor supply to a city. Second, and for the same reason, it follows as a corollary to Henderson [3] capitalization rule (mentioned in the introduction) that wage differentials across cities compensate for differences in marginal housing costs, rather than for differences in average housing costs. The exact compensating factor which is capitalized into intercity wage differences is either the sum of housing plus commuting costs at the very edge of the city, or its equivalent in the form of housing cost at the very center. Note that each of these equivalent alternatives (evaluated at marginal points in the city space) would always exceed any conceivable measure

4. In the case of a "closed city" the formal derivation of equation (8) is slightly more involved since a rental premium on urban land over agricultural land, say $B$, may exist along the boundary of a city. That is, $r(D)=1+B>1$, and instead of $E(N, A)$ we get $E(N, A, B)=e\left(1+B, U^{*} ; N, A\right)$. Substituting these terms in (8), the analysis can then proceed unchanged. 
of average housing costs in a city. While this corollary, which follows from (9) in a straightforward way, is of particular interest from the viewpoint of labor markets analysis, it also provides a remarkably simple procedure by which the urbanization deflator can be estimated..$^{5}$

Finally turning to the urbanization deflator itself, we note that the wage reservation function $w=E(N, A) /[1-D(N)]$ can also be interpreted as a hedonic measure of its arguments: city size $(N)$ and natural amenities $(A)$. Controlling for the effects of natural amenities the effect of city size on the quality of life can be evaluated through (negatively signed) wage differences, without a need to control for housing costs. Formally, these effects are obtainable by totally differentiating equation (8) and rearranging terms:

$$
d(\log w)=\left[\partial(\log E) / \partial N+D^{\prime} /(1-D)\right] d N+[\partial(\log E) / \partial A] d A .
$$

From the properties of the expenditure function we know that the partial derivatives on the right hand side of (10) have the dimensionality of money metric marginal utility. In particular, $\partial(\log E) / \partial N$ represents the rate of compensation in money income for utility lost (or gained) due to the changing endowment of size amenities in a growing city, whereas $D^{\prime} /(1-D)=w D^{\prime} / E$ represents the rate of compensation in money income for increasing commuting costs to the edge of such a city. Similarly, $\partial(\log E) / \partial A$ represents the rate of compensation in income for the changing endowment of natural amenities as a consumer moves across cities of equal size. The sign of $\partial(\log E) / \partial A$ is clearly negative, and since $D<1$, the sign of $D^{\prime} /(1-D)$ is clearly positive. It is difficult however to predict the sign or magnitude of $\partial(\log E) / \partial N$. Consequently, the sign of the entire coefficient of $d N$, which contains the important information about the effect of city size on the quality of life, is an empirical question subject to estimation. ${ }^{6}$ While data relevant to estimation of an equation such as (9) seem to be available, the statistical question of whether the resulting estimate would actually identify a supply function must now be addressed.

\section{City Demand for Labor and the Identification Problem}

What are the conditions under which labor supply to a city (equations (8) or (10)) is observationally identifiable. At issue is the interaction between demand and supply in a system of imperfectly segmented labor markets. Our treatment of this issue is based on the argument that the incidence of labor supply is national in essence, whereas the incidence of demand is largely localized in the short-run and at least partly localized in the long-run. Geographic mobility of modern workers is the main reason why labor supply is considered to be universal throughout a modern system of cities. As to the demand, we can list the following considerations.

The local nature of the demand for labor is first and foremost a result of local specialization in production. In a sense, cities are diversifiers in consumption (which is one reason why labor is mobile) but specialists in production. Triggered by industry specific local comparative advantages, specialization is realized in the fact that cities differ widely in their industrial mix. ${ }^{7}$ Since different industries use different technologies of production of which factor demand is a derivative, it

5. Incidentally, this corollary remains intact even in a more general model where the "open city" assumption is relaxed. To follow the discussion in Footnote 4 , the term $E(N, A)$ on the right hand side of equation (9) is replaced in the case of a "closed city" by $E(N, A, B)$. This extension indicates that the premium $(B)$ on urban land due to restricted accessibility is properly capitalized into wages.

6. In a separate paper (Kahn and Ofek [7]) it has been demonstrated that such a coefficient is positive under equilibrium conditions plausible to small and medium size cities, but not necessarily to large ones.

7. The extent to which cities in the U.S. differ in their industrial mix and levels of specialization in production has been demonstrated by Simon [14]. 
follows that variations across cities in the industrial mix must evolve into different aggregate demand functions for factors in general and for labor in particular. Such local differences in the industrial mix along with the differences in the demand for labor they entail are sustained in the short-run by the immobility of capital, and in the long-run by the specificity of producer natural amenities as well as by agglomeration economies.

The considerations outlined above establish a situation in which a universal labor supply function interacts with a multitude of local demand functions. Under these conditions identification is not an overly serious statistical problem, and a cross-sectional estimation of an equation such as (10) can be reasonably expected to identify the supply of labor. This conclusion provides a general justification for the specification and procedures of estimation to be carried out in the empirical part of this study, as well as a basis for interpretation of the final findings.

\section{Empirical Analysis}

A lesson repeatedly learned in the analysis of spatial problems is that initial intuitive expectations are often misconceived. A case in point is the elasticity of labor supply in a system of cities. Following conventional economic intuition one might initially expect perfect labor mobility to result in an infinitely elastic labor supply to a single city in the system. Yet, as we have seen in the preceding part of this paper, a more careful analysis of the problem indicates that even under conditions most favorable to competition (including perfect mobility of labor) an infinitely elastic labor supply to a city is the exception rather than the rule. The seeming contradiction is explained by the presence of a city size argument in the utility function of a household and commuting cost in its budget constraint. Specifically, to use equation (10), the elasticity is (identically) equal to infinity only when workers are indifferent to city size and marginal cost of commuting is zero $\left(\partial E / \partial N=w D^{\prime}=0\right)$. The elasticity may also equal infinity at singular points where the marginal amenity of city size is positive and sufficiently large to just about offset marginal commuting costs $\left(\partial E / \partial N+w D^{\prime}=0\right)$. In general, however, the elasticity is finite taking on either a positive or negative sign.

Put differently, labor supply to a city may actually slope upward or downward, depending on whether the net marginal effect of city size $\left(\partial E / \partial N+w D^{\prime}\right)$ is positive or negative. Over the relevant range of city size, the slope may alternate in sign reflecting changes in the marginal balance of utility gains and losses. Whether the labor supply in this instance is U-shaped, or inverted U-shaped (or, perhaps, sinusoidal in shape) is of special interest because it signifies the existence of "best" or "worst" levels of city size in terms of quality of life. The parameters of the labor supply function, including slopes and possible extrema points, are estimated in the following analysis and serve as a basis for the construction of the urbanization deflator.

\section{Specification}

An estimatable specification of the city aggregate labor supply function $w=E(N, A) /[1-D(N)]$ is obtained by linearizing and integrating equation (10):

$$
\log w=\beta_{0}+\beta_{1} N+\beta_{2} A+u,
$$

where the intercept $\beta_{0}$ is expected to be positive, ${ }^{8} \beta_{1}$ and $\beta_{2}$ are the two coefficients interpreted

8. Setting $N=0$ and $A=0$, the intercept $E(N, A) /[1-D(N)]=E(0,0)=\beta_{0}$ should be equivalent to the rural wage rate at zero level of natural amenities. 
in the theoretical discussion following Equation (10), and $u$ is an error term. An extension of this specification to a greater number of variables readily suggest itself. Additional variables are included in order to relax the assumption of labor homogeneity as well as to control for other complicating factors overlooked in the theoretical model. The extended version we have actually estimated is presented and explained below.

$$
\log w=\beta_{0}+\beta_{1} \mathbf{X}+\beta_{2} \mathbf{N}+\beta_{3} \mathbf{A}+u,
$$

where

$w=$ expected wages $=($ wages $) \times(1$-unemployment rate $) .{ }^{9}$

$\mathbf{X}=\mathbf{a}$ vector of individual human capital characteristics to control for interpersonal differences in productivity, and to a lesser extent, in tastes. Included are schooling, work experience $(=$ age - schooling -6$)$, nonlabor income, and occupation type.

$\mathbf{N}=$ a vector of city size variables, incorporated in polynomial forms (of up to 3rd order). Also included in this set is the rate of growth in city size in terms of migration. The main reason for the inclusion of the growth variable is to control for wage differentials that are still inducing net influx (or outflow) of migrants. Since such differentials signify dynamic deviations from long-run equilibrium, there is no justification to include them as permanent differentials that account for quality of life.

$\mathbf{A}=$ a vector of natural consumer amenities specific to the site a city is located on, but independent of city size. These include the amount of sunshine, log of January temperature, yearly inches of rain, and a dummy variable for coastal states to control for humidity and for the moderating effects of oceans.

$u=$ an error term with the usual properties.

\section{Data and Empirical Findings}

A labor supply function of the general form suggested above was estimated using a subsample from the 1980 PUMS (Public Use Microdata Sample) data. ${ }^{10}$ PUMS reports individual data and identifies residential location for respondents in 282 of the 316 possible SMSA's (each of the remaining 34 SMSA's is paired with a nearby SMSA's so the combined population exceeds 100,000). ${ }^{11}$ The geographic identification of individuals at the SMSA level makes it possible to combine personal characteristics of a resident with those characteristics of the city thought to influence quality of life: city size, climate, and other geographic amenities specific to the site a city is located on. ${ }^{12}$ Equation (12) was fitted to the PUMS data producing the results presented in Table I. These estimates of the labor supply function indicate that a linear specification is positively sloped, a quadratic specification has an inverted U-shape, and a cubic specification is sinusoidal in nature (see Figure 1).

The linear approximation (Column 1) produced a positive coefficient of wages on size which is significantly larger than zero. Wages are expected to rise, on the average and notwithstanding

9. Both hourly wage and annual earnings were used as dependent variables. Since differences in the main results were minimal (as expected for a sample of full time workers), we chose to report here only the hourly earnings version.

10. Our subsample is confined to white males over 17 who are heads of households and work full time. Full time workers are defined as those reporting 35 or more hours per week and 40 or more weeks per annum.

11. Alaska and Hawaii have been eliminated since wages may differ due to market separation and imperfect mobility.

12. Geographic characteristics were taken from the State and Metropolitan Area Databook 1978-1980, and the Statistical Abstract of the United States 1980. 
Table I. Regression Analysis: 1980 PUMS Data (Based on 12,299 observations and 16 additional controls) ${ }^{\text {a }}$

\begin{tabular}{lccc}
\hline & \multicolumn{3}{c}{ Regression form } \\
& \multicolumn{3}{c}{$T$ values in ()} \\
\cline { 2 - 4 } & LINEAR & QUADRATIC & CUBIC \\
Dep-variable: In hourly wageb & $(1)$ & $(2)$ & $(3)$ \\
\hline INTERCEPT & 2.399 & 2.441 & 2.357 \\
& $(5.87)$ & $(6.01)$ & $(5.79)$ \\
EDUCATION & 0.046 & 0.045 & 0.045 \\
& $(28.8)$ & $(28.5)$ & $(28.4)$ \\
EXPERIENCE & 0.038 & 0.038 & 0.038 \\
EXPERIENCE SQ & $(33.7)$ & $(33.5)$ & $(33.5)$ \\
& -.00059 & -.00059 & -.00059 \\
LOG JAN TEMPERATURE & $(24.8)$ & $(24.6)$ & $(24.7)$ \\
SUNSHINE & -.010 & -.070 & -.073 \\
& $(.474)$ & $(3.12)$ & $(3.23)$ \\
RAIN & -.0012 & -.0006 & -.0010 \\
& $(1.14)$ & $(.676)$ & $(.952)$ \\
POPULATION GROWTH & .0003 & .0017 & .0017 \\
NONLABOR INCOME & $(.424)$ & $(2.50)$ & $(2.41)$ \\
POPULATION & -1.455 & -1.493 & -1.428 \\
POPULATION SQ & $(3.36)$ & $(3.46)$ & $(3.31)$ \\
POPULATION CUBE & 0.014 & 0.014 & 0.014 \\
ADJ. R SQ & $(12.4)$ & $(12.3)$ & $(12.2)$ \\
\hline & 0.0087 & 0.068 & 0.099 \\
& $(4.76)$ & $(12.4)$ & $(8.61)$ \\
& - & -.007 & -.018 \\
& -27 & $(11.5)$ & $(5.08)$ \\
& -00085 \\
& -28 & -28 & $(3.05)$ \\
\hline
\end{tabular}

a. The additional controls and the corresponding estimated coefficients are listed in Key II, below.

b. For definitions of the main variables, see Key I below.

KEY I: Variables Reported in the Body of the Table

WAGE $=$ annual earnings/annual hours of work; EDUCATION $=$ years of schooling; EXPERIENCE $=$ years in the labor force (age - education - 6); LOG JAN TEMPERATURE = log of average January temperature; SUNSHINE = percent of annual sunny days; RAIN = Inches of annual precipitation; POPULATION GROWTH = percentage change in population, 1970-1978; NONLABOR INCOME = income from sources other than work (consisting of pension, interest, and dividends); POPULATION = SMSA population (mil.)

KEY II: Additional Controls ( $b=$ coef. in cubic estimation, $t=t$-value)

Regional Dummies: COASTAL STATE $(b=.044, t=3.7)$; NEWENGLAND $(b=-.072, t=3.8)$; ENCENTRAL $(b=.058, t=4.6)$; ESCENTRAL $(b=.020, t=1.0)$; WNCENTRAL $(b=.018, t=0.9)$; WSCENTRAL $(b=$ $.060, t=4.0)$; MOUNTAIN $(b=.100, t=3.4)$; PACIFICNL $(b=.113, t=5.5$ ); MIDATLANTIC (left-out).

Occupational Dummies: MANAGER $(b=.23, t=9.1)$; PROFESS $(b=.18, t=6.8)$; TECHNIC $(b=.14, t$ $=4.6)$; SALES $(b=.09, t=3.4)$; CLERK $(b=.03, t=1.0) ; \operatorname{SERVICE}(b=-.12, t=4.4)$; CRAFT $(b=.14, t$ $=5.8)$; OPERATOR $(b=.07, t=2.9)$; TRANSPORT $(b=.07, t=2.5)$.

nonlinearities, by about 0.9 percent for each increment of a million in city size. This implies an equivalent drop in quality of life, holding wages constant.

For small cities the impact of growth in size may be larger. Moving to the nonlinear estimates (columns 2 and 3), it can be seen by extrapolation that for the small city (say, population = $100,000)$ the wage increase is estimated at a rate of 6.6 to 9.5 percent per million, depending on the specification.

The rate at which wages increase with city size levels off as cities become larger, reaching 


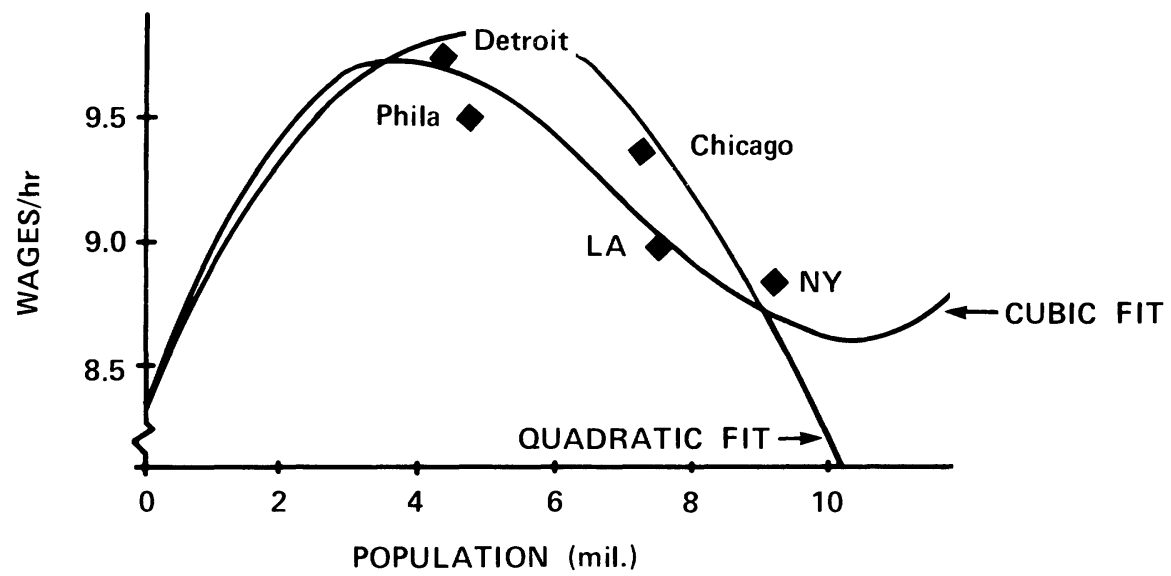

Figure 1. Least squares fit of hourly wages (full time workers) on city size adjusted at mean for the 24 additional controls listed in Table I. The point estimates for the 5 largest U.S. metropolitan areas have been obtained independently using dummy variables rather than polynomial specifications.

a peak in the population range of 3.7 to 4.9 million. This is interpreted to be the worst city size range in terms of quality of life. The only U.S. cities falling in this range are Detroit and Philadelphia. It is important to note that most cities (and population) in the U.S. are located to the left of this range, along the rising segment of the aggregate labor supply function (Figure 1).

Though not always significant, all the other explanatory coefficients assumed expected signs. The human capital variables (education, experience and experience squared) were all of the appropriate sign, significant, and consistent with the standard findings in the literature dealing with the analysis of human capital and the estimation of earning functions from individual data [9; 13]. The climatic variables, although not all significant, were correctly signed. The log of January temperature was negative and for the most part significant. The variable was entered logarithmically to account for expected nonlinearity in willingness to pay to avoid cold. The amount of sunshine and the amount of rain (an amenity and a disamenity, respectively) were both consistently signed though not always significant. Nonlabor income was included to control for the pure income effect on the willingness to accept larger city size. In addition to regional controls, occupational dummy variables were included to control for differences in marginal productivity due to occupation-specific cyclical or structural effects in the labor market. ${ }^{13}$

Finally, a growth variable was included to control for possible existence of disequilibria. If quality of life is a normal good in consumption, then cities which offer superior amenities, other things equal, would tend to grow faster than the country as a whole, due to the income effect. Hence the negative sign of the coefficient.

\section{The Urbanization Deflator of the GNP}

The extent to which the GNP provides a measure of welfare is a question that has become a focus of renewed interest over the last decade or so-primarily due to Nordhaus and Tobin [10]. Two empirical findings in that study seem to have influenced the way economists view urbanization and its possible impact on real national income. The first finding reported by Nordhaus and Tobin

13. For a full list of occupational, regional, and other controls used in the estimation, see footnotes to Table I. 
indicates that the urban disamenity adjustment (8 percent in 1960) is not an insubstantial fraction of income. The second finding they have reported indicates, however, that over time (i.e., 1929 to 1965) that fraction has not risen. New micro-data sets such as the PUMS make it possible to use more detailed estimation procedures and to extend the investigation over a longer period in time. Nordhaus-Tobin estimates can thus be corroborated and put in a slightly broader historical perspective.

We have estimated the welfare effects of urbanization by projecting the estimated parameters of the labor supply function on the changing civic distribution of the U.S. population. Since the coefficients of city size in the estimated labor supply function has the dimensionality of moneymetric utility, it can serve as a specific city size welfare deflator. Application of this deflator to the actual distributions of the population in different years should yield an overall GNP deflator comparable to that suggested by Nordhaus-Tobin.

Table II provides the results obtained for nine selected years 1910 through 1984 . While the main body of the table (and the notes that follow it) serve to outline data sources and computation procedures, the last two lines at the bottom of the table list the main findings in the form of a deflator for each year under investigation $(1910,1920,1930,1940,1950,1960,1970,1980$, and 1984). These findings indicate that most recently the deflator was on the order of about 6.7 percentage points of the GNP - roughly the equivalent of 200 billion dollars in 1984! Since detailed SMSA data are not available for the years prior to 1950, the deflators for those years are based on the definition of "urban-place" rather than SMSA. Such a switch in definitions resulted in a technical drop of 0.4 percentage point in the level of the deflator in 1950 (see Table II, columns 7 and 8). The net change in the deflator over the entire period, from 4.1 in 1910 to 6.7 in 1984, represents therefore an increase on the order of 3 percentage points $(6.7-4.1+0.4$ $=3.0$ ). Over time, as it turns out, the deflator has been climbing at almost a steady rate of half a percentage point per decade. The main exception to this rule were the two consecutive decades 1930 to 1950. These two "traumatic" decades (due to the Great Depression and World War II) are known of course to be special in many other respects.

In what ways are these results in agreement, or in disagreement, with the results reported in the Nordhaus-Tobin study? Generally speaking, we find our estimates to be slightly more conservative with regard to the magnitudes of the deflators, but less conservative with regard to the rates at which the deflators change over time. For instance, estimated in Nordhaus-Tobin study the general deflator for 1960 is found to be on the order of about 8 percent, as compared with 5.4 percent in the present study. Similarly, Nordhaus and Tobin found that "If the population were completely urbanized, the adjustment would be about one-third of income" [10, 54]. Our findings indicate a maximum adjustment of only one-sixth of income, and even this may occur only under the (hypothetical) situation where the entire population would reside in cities as large as "worst city size" (about 4 million). Given the fact that the two studies differ, save the fundamental premise, in almost all imaginable details of the concrete empirical analyses (data, definitions, specification, units of observation, timing, etc.), the differences in the final findings are surprisingly small. Moreover, the construction of the urbanization deflator in both studies are subject to relatively high and independent margins of error that could have easily produced differences which are even larger. ${ }^{14}$

14. A weak spot already pointed out by Nordhaus-Tobin $[10,51,54]$, which is equally shared by our study, is the attempt to draw inferences about a trend over time on the basis of a cross section in a single year. (Nordhaus-Tobin reference year is 1960, ours is 1980). Note also that Nordhaus-Tobin [10,59] considered their correction for the urban disamenity to be about ten times the percentage error of the GNP. 
Table II. The Urbanization Deflator of the GNP and the Distribution of the Population by City Size, Selected Years: 1910-1984

\begin{tabular}{|c|c|c|c|c|c|c|c|c|c|c|c|c|}
\hline \multirow{3}{*}{$\begin{array}{l}\text { POPULATION } \\
(1,000)\end{array}$} & \multirow{3}{*}{$\begin{array}{l}\text { DEFLATOR } \\
\text { BY SIZE } \\
\text { OF PLACE }^{b}\end{array}$} & \multicolumn{10}{|c|}{ PERCENT OF TOTAL POPULATION } & \multirow{3}{*}{$\begin{array}{c}\text { DEFLATORS } \\
\text { BY SIZE } \\
\text { OF SMSA }^{\text {a }}\end{array}$} \\
\hline & & \multicolumn{5}{|c|}{ PREVIOUS URBAN DEFINITIONS } & \multicolumn{5}{|c|}{ CURRENT SMSA DEFINITIONS } & \\
\hline & & 1910 & 1920 & 1930 & 1940 & 1950 & 1950 & 1960 & 1970 & 1980 & 1984 & \\
\hline (1) & (2) & (3) & (4) & (5) & (6) & (7) & (8) & (9) & $(10)$ & $(11)$ & $(12)$ & (13) \\
\hline $8,000-10,000$ & .071 & 0 & 0 & 0 & 0 & 0 & 6.3 & 5.3 & 4.4 & 3.7 & 3.5 & .065 \\
\hline $7,000-8,000$ & .078 & 0 & 0 & 0 & 5.6 & 5.2 & 0 & 0 & 3.5 & 3.3 & 3.3 & .097 \\
\hline $6,000-7,000$ & .084 & 0 & 0 & 5.6 & 0 & 0 & 0 & 6.8 & 3.0 & 2.7 & 2.6 & .123 \\
\hline $5,000-6,000$ & .106 & 0 & 5.3 & 0 & 0 & 0 & 4.2 & 0 & 0 & 0 & 0 & .146 \\
\hline $4,000-5,000$ & .154 & 5.2 & 0 & 0 & 0 & 0 & 9.0 & 4.6 & 4.6 & 4.1 & 3.9 & .162 \\
\hline $3,000-4,000$ & .229 & 0 & 0 & 2.7 & 2.6 & 2.4 & 0.0 & 0.0 & 3.0 & 2.9 & 2.8 & .165 \\
\hline $2,000-3,000$ & .310 & 2.4 & 2.6 & 0 & 0 & 1.4 & 4.4 & 7.6 & 7.2 & 9.3 & 9.9 & .150 \\
\hline $1,000-2,000$ & .338 & 1.7 & 1.7 & 3.9 & 3.8 & 2.5 & 5.4 & 10.0 & 14.0 & 15.9 & 16.0 & .111 \\
\hline $500-1,000$ & .255 & 3.3 & 5.9 & 4.7 & 4.9 & 6.1 & 8.2 & 10.7 & 10.8 & 12.9 & 13.5 & .065 \\
\hline $250-500$ & .150 & 4.3 & 4.3 & 6.5 & 5.9 & 5.4 & 9.6 & 8.8 & 9.7 & 10.6 & 10.4 & .035 \\
\hline $100-250$ & .071 & 5.2 & 6.1 & 6.2 & 6.0 & 6.6 & 7.6 & 8.1 & 7.4 & 9.6 & 9.4 & .017 \\
\hline $50-100$ & .008 & 4.6 & 5.0 & 5.3 & 5.6 & 6.0 & 1.1 & 1.0 & 1.0 & 0.9 & 0.9 & .007 \\
\hline
\end{tabular}




\begin{tabular}{|c|c|c|c|c|c|c|c|c|c|c|c|c|}
\hline $25-50$ & .003 & 4.4 & 4.8 & 5.2 & 5.6 & 6.5 & 0 & 0 & 0 & 0 & 0 & .003 \\
\hline $5-25$ & .001 & 10.6 & 11.3 & 12.2 & 12.7 & 13.6 & 0 & 0 & 0 & 0 & 0 & .001 \\
\hline Under 5,000 and rural & $.0006^{\mathrm{d}}$ & 58.3 & 53.0 & 47.7 & 47.3 & 44.3 & (NA) & (NA) & (NA) & (NA) & (NA) & \\
\hline Non-SMSA pop. & (NA) & (NA) & (NA) & (NA) & (NA) & (NA) & 44.2 & 37.0 & 31.4 & 24.1 & 23.8 & $.001^{\circ}$ \\
\hline Total pop. & & 100.0 & 100.0 & 100.0 & 100.0 & 100.0 & 100.0 & 100.0 & 100.0 & 100.0 & 100.0 & \\
\hline 1910-50 GNP Deflator ${ }^{\mathrm{e}}$ & & 4.1 & 4.6 & 5.1 & 5.0 & 5.2 & (NA) & (NA) & (NA) & (NA) & (NA) & \\
\hline 1950-84 GNP Deflatorf & & (NA) & (NA) & (NA) & (NA) & (NA) & 4.8 & 5.5 & 6.1 & 6.6 & 6.7 & \\
\hline
\end{tabular}

SOURCES: Statistical Abstract of the U.S.A.: 1986 (Tables 19, 20, 24); 1985 (Tables 18, 19, 22); 1975 (Table 20); 1964 (Table 10); and 1951 (Tables 55, 56). Historical Statistics, Colonial Times to 1970: series A 43-72 and A 264-275. The deflators (Columns 2 and 13) are based on Table I, this study.

a. Extrapolated at mid-point for each SMSA size-interval on the basis of the coefficients of "population" "population sq" and "population cube," Column 3, Table I.

b. Derived from the SMSA deflators (see footnote a, above), but adjusted for the change in the urban definition. Specifically, the adjustment was based on coefficients estimated by regressing the distribution of the population classified by the definition of "urban place" (effective in years prior to 1950) on the corresponding distribution by SMSA (effective since 1950). The estimation was conducted on 1950 data, a year for which the data on the two distributions overlap.

c. The deflator for the non-SMSA population (.001) was calculated for median city size of 10,000 . Two alternative assumptions-city size 0 , and city size 50,000-would have changed the deflator to 0 and .005 , indicating possible errors on the order of two tenth a percentage point in the final estimation of the GNP deflator, at most.

d. The rural deflator (.0006) was calculated for median population size of 2,500 .

e. The averages of Column 2 weighted by the column corresponding to each year, respectively.

f. The averages of Column 13 weighted by the column corresponding to each year, respectively. 
The only substantial issue on which the two studies seem to differ, not only in degree but also in kind, is the way the deflator behaves over time. Nordhaus-Tobin findings indicate that “. . . the correction as a fraction of income has not risen since 1929 [and through 1965]" [10, 54]. For the most part this period overlaps with the two decades (1930 through 1950) for which our findings show similar stagnation, as pointed out above. However, by extending the period under investigation back to 1910 , and forward to 1984, it was found that these two decades are the exception rather than the rule. During the remaining part of the period, which covers the better part of the 20th century, our findings show a steady though modest growth (of half a percentage point per decade) in that correction.

\section{References}

1. Freeman, A. M., "On estimating Air Pollution Control Benefits from Land Value Studies." Journal of Environmental Economics, May 1974, 74-83.

2. Hall, Robert E., "Why is Unemployment So High at Full Employment?" Brookings Economic Papers, Sept.Dec. 1970, 369-410.

3. Henderson, J. Vernon, "Evaluating Consumer Amenities and Interregional Welfare Differences." Journal of Urban Economics, January 1982, 32-59.

4. Henning, John A. and Ronald G. Ridker, "The Determinants of Residential Property Values with Special Reference to Air Pollution." Review of Economic and Statistics, May 1967, 246-57.

5. Hoch, Irving J., "Income and City Size." Urban Studies, October 1972, 299-328.

6. Hochman, Oded and Haim Ofek, "The Value of Time in Consumption and Residential Location in an Urban Setting." American Economic Review, December 1977, 996-1003.

7. Kahn, James R. and Haim Ofek. "The Equilibrium Distribution of Population and Wages in a System of Cities." Unpublished paper, SUNY Binghamton, 1986.

8. Lucas, Robert E. B., "Hedonic Wage Equations and Psychic Wages in Returns to Schooling." American Economic Review, September 1977, 549-558.

9. Mincer, Jacob. Schooling, Experience and Earnings. New York: National Bureau of Economic Research, 1974.

10. Nordhaus, William and James Tobin. "Is Growth Obsolete?" in Fiftieth Anniversary Colloquium V. New York: National Bureau of Economic Research, 1972.

11. Polinsky, Mitchell and Daniel L. Rubinfeld. "Property Values and the Benefits of Environmental Improvements: Theory and Measurement," in Public Economics and the Quality of Life, edited by L. Wingo and A. Evans. Baltimore: Johns Hopkins University Press, 1977.

12. Roback, Jenifer, "Wages, Rents and the Quality of Life." Journal of Political Economy, December 1982, 125778.

13. Rosen, Sherwin. "Wage Based Indexes of Urban Quality of Life," in Current Issues in Urban Economics, edited by P. Mieszkowski and M. Straszheim. Baltimore: The Johns Hopkins University Press, 1979, pp. 74-104.

14. Simon, Curtis J. "Industrial Diversity and Metropolitan Unemployment." Unpublished Ph.D. Dissertation, SUNY Binghamton, 1985.

15. Thaler, Richard and Sherwin Rosen. "The Value of Saving a Life: Evidence from the Labor Market," in Household Production and Consumption, edited by N. Terlecky. New York: Columbia University Press, 1975, pp. $265-98$. 